\title{
Aroma Evaluation of Young Chinese Merlot Wines with Denomination of Origin
}

\author{
L. Zhang*, Y.S. Tao, Y. Wen, H. Wang \\ College of Enology, Northwest A\& F University, 712100, Shaanxi Province, China
}

Submitted for publication: July 2012

Accepted for publication: October 2012

Key words: Chinese Merlot wine, aroma compound, odour active value, sensory analysis

\begin{abstract}
Merlot wines from four premium wine-producing districts in China were analysed for their volatile composition and sensory properties. Fifty-seven aroma compounds were quantified by SPME-GC-MSOAV analysis, which showed that thirty of these compounds were active on the basis of their odour active value (OAV). According to the aroma descriptions of eleven impact odorants in all the sample wines, the collective aroma characteristics of Chinese Merlot red wine are complex. Its main flavour is that of some tropical and temperate fruits, such as banana, pineapple, green apple, pear and strawberry, along with a lactic flavour from the malolactic fermentation. It also has some traits of processed fruits, Muscat and floral pollen flavour. Moreover, different districts gave Merlot wine distinct characters. Changli wine had a higher intensity and complexity of global aroma, a strong fruity aroma, and an obvious nuance of lactic and nut traits. The sine from Helanshan had weak fusel flavour and some lemon fruity flavour. Shacheng wine had weak fusel flavour, along with green grass and some fruity flavour of raspberry and violet. Manasi wine had the odour of unpleasant fatty acids and phenol due to its high content of fatty acids and volatile phenol. The sensory analysis confirmed the aroma prediction from the active odorants of the sample wines. Changli wine had the highest sensory scores, while Manasi wine had the worst evaluation of aroma, taste and harmony. The results suggest that the Merlot variety is more suitable for planting in Changli than in the Manasi region.
\end{abstract}

\section{INTRODUCTION}

The main wine-making grape variety in China is Vitis vinifera $\mathrm{L}$, which originated from Europe. Merlot is a popular cultivar in the main wine-producing districts in China. The earliest odour studies of Merlot and Cabernet Sauvignon wines in Bordeaux indicated that the wine had a fruity and flowery aroma, with a marked toasty, caramel, smoky, roast and herb flavour (Peynaud, 1980; Allen et al., 1994; Lopez et al., 1999). Merlot Wine in the State of California and in Australia has a rich fruity flavour, with caramel, grassy and soil nuances. Volatile analysis demonstrated that the content of ethyl octanoate in Merlot wine was four to five times higher than that in Cabernet Sauvignon wine (Gurbuz et al., 2006).

A number of studies have indicated that the volatiles in wine are responsible for the characteristic bouquet of wines. There is a relationship between specific volatile compounds and aroma in the wine, and therefore some sensory descriptors can be predicted by gas chromatographic data. Thus far nearly 1000 volatile substances have been reported in wine, and their concentrations range from ng/L to $\mathrm{mg} / \mathrm{L}(\mathrm{Li}, 2006)$. It has been demonstrated that the profile of aroma components in wine is influenced by origin, variety, vintage, viticultural technology and the winemaking process (Guth, 1997; Perestrelo et al., 2006). The aroma characters of wine have been used to identify different wine products (Diaz et al., 2003; Escudero et al., 2004). In many complex wines there are no key compounds that can dominative the aroma, which rather is contributed by the mixture of different odorants. A comparison of aroma compounds in different wines concluded that there were concentration differences of some volatiles among the wines. The most significant differences are quantitative rather than qualitative (Lopez et al., 1999; Ferreira et al., 2000). To estimate the contributions of the volatiles in wine, the odour active value (OAV) was introduced. It is the ratio between the measurement of the concentration of volatiles in wines and their odour threshold. The contribution of volatiles to the final aroma depends on whether their concentration in the wine is above the perception threshold (Tao \& Zhang, 2010). Only those odorants with an OAV $>1$ can be perceived (Guth, 1997; Li, 2006; Vilanova \& Martinez, 2007). Culleré studied the volatile compounds of six premium Spanish red wines with denomination of origin, and proved that forty aroma compounds were impact odorants (Culleré et al., 2004).

*Corresponding author: E-mail: zhanglgrace@163.com [Tel: 86-15229271810; Fax: 86-029-87091994]

Aknowledgements: This project was supported by the China National Science Fund (31000756) and the Elementary Science Research Fund of NWSUAF (QN2009061). The authors are grateful to Huaxia Winemaking Company (Changli County), Rongcheng Winemaking Company (Shacheng County), Xixiawang Winemaking Company (Helanshan) and Xintian Winemaking Company (Manasi) for the supply of the samples used in this study. Zhiming Xu of Louisiana State University is thanked for reviewing the manuscript 
Chinese Merlot wine characteristics have not been described much in the past ten years, although some articles on the aroma compounds of this wine cultivar from other areas have been published (Wang et al., 2005). In this work, Merlot wines from different origins were sampled. Using OAV analysis of the volatile compounds, some active odorants of this mono-varietal red wine in China were revealed. The aim was to predict wine flavour features from those impact odorants using their odour description. The aroma evaluation of the wine was also subjected to testing by sensory analysis.

\section{MATERIALS AND METHODS \\ Wines}

Wine samples were collected from the four main wineproducing districts in China. Samples were supplied by Huaxia Winemaking Company (Changli County), Rongcheng Winemaking Company (Shacheng County), Xixiawang Winemaking Company (eastern region of Helanshan maintain), Xintian Winemaking Company (Manasi County). All samples were produced in 2006 and were collected in the tenth month after alcoholic fermentation. General indexes, such as reducing sugars, ethanol, density, extract, titratable acidity, $\mathrm{pH}$, volatile acidity, total and free $\mathrm{SO}_{2}$ were determined with the methods provided by the Office International de la Vigne et du Vin (O.I.V., 1990). Values of all indexes were measured up to the Wine Product Standards in China (GB/15037-2006), and no significant differences were found among these samples.

\section{Wine making}

Healthy Merlot grapes were obtained from the vineyard. The grapes were destemmed and crushed in a commercial grape destemmer-crusher. The juice was then pumped to stainless steel tanks. The must was treated with sulphur dioxide ( $45 \mathrm{mg} / \mathrm{L})$ in $\mathrm{H}_{2} \mathrm{SO}_{3}(6 \%)$ form and soaked for approximately $24 \mathrm{~h}$ at $20^{\circ} \mathrm{C}$. Alcoholic fermentation was carried out at 25 to $30^{\circ} \mathrm{C}$ after the yeast (Saccharomyces cerevisiae VR5, Netherlands, $0.2 \mathrm{~g} / \mathrm{L}$ ) was added, and followed by spontaneous malolactic fermentation at 18 to $20^{\circ} \mathrm{C}$. The wines were then racked and sulphur dioxide $(75 \mathrm{mg} / \mathrm{L})$ was added. Wines were stored in stainless steel tanks at $15^{\circ} \mathrm{C}$. Racking and stabilising processes were carried out prior to analysis.

\section{Apparatus}

GC-MS: TRACE DSQ (Thermo-Finnigan, USA). Analytical column: DB-Wax capillary column $(30 \mathrm{~m} \times 0.32 \mathrm{~mm}$ i.d., $0.25 \mu \mathrm{m}$ film thickness) (J\&W, Folsom, USA); SPME, Supelco Company, USA; solid phase extraction fibre: PDMS (100 $\mu \mathrm{m}$ polydimethylsiloxane), Supelco Company.

\section{Reagents}

All reagents used were analytical grade. Absolute ethanol, tartaric acid and sodium chloride were purchased from Xi'an chemical factory (Xi'an, China). Water was obtained from a Milli-Q purification system (Millipore). Solvents did not require additional distillation. The 34 pure reference compounds were from Sigma-Aldrich (China sector): ethyl acetate, ethyl butyrate, isoamyl acetate, phenylethyl acetate, ethyl hexanoate, ethyl lactate, ethyl octanoate, ethyl DL-3-hydroxybutyrate, ethyl decanoate, diethyl succinate, ethyl laurate, ethyl palmitate, isoamyl lactate, isoamyl octanoate, 1-propanol, 1-butanol, isobutanol, isopentanol, 1-hexanol, 1-heptanol, 3-octanol, 1-decanol, benzyl alcohol, $\beta$-phenyl ethanol, lauryl alcohol, furfural, cis-geraniol, linalool, $\beta$-damascenone, hexanoic acid, octanoic acid, decanoic acid, lauric acid, and $p$-ethyl phenol.

\section{Standard solutions}

Exact volumes of the standard chemical compounds were dissolved in synthetic wines to prepare the calibration data. The synthetic wine had 12\% (v/v) alcohol and $6 \mathrm{~g} / \mathrm{L}$ of tartaric acid. Its $\mathrm{pH}$ was 3.3 to 3.4 , adjusted with $1 \mathrm{M} \mathrm{NaOH}$. These standard compounds were dissolved in synthetic wines at concentrations at three orders of magnitude higher than typically found in wines. For quantification, five-point calibration curves were prepared for each compound. Octan3-ol was employed as an internal standard because it was not the typical volatile compound in the wine and has a perfect ion peak shape and peak place in the total ion chromatograph (TIC). Exact volumes of octan-3-ol were dissolved in absolute ethanol. All these solutions were stored in darkness at $4^{\circ} \mathrm{C}$.

\section{SPME extraction}

SPME was performed following the methods described previously. Both wine samples and model solutions were analysed in $15-\mathrm{mL}$ glass vials, filled with $10 \mathrm{ml}$ of each sample and $2 \mathrm{~g}$ of $\mathrm{NaCl}$. For SPME analyses, the vials were dipped in a thermostatic water bath. A magnetic stirring bar was placed in the vial to agitate the sample. PDMS $(100 \mu \mathrm{m}$ polydimethylsiloxane) was used as the solid-phase fibre for micro-extraction. The vial was equilibrated at $40^{\circ} \mathrm{C}$ for $10 \mathrm{~min}$, after which the power magnetic stirrer was added. SPME was performed at $40^{\circ} \mathrm{C}$ for $30 \mathrm{~min}$, and then the solidphase fibre was immediately put into the gas chromatograph injector. The fibre remained in the injector for about $3 \mathrm{~min}$.

\section{GC-MS analysis}

Carrier: He at $1 \mathrm{~mL} / \mathrm{min}$. The temperature program used was $40^{\circ} \mathrm{C}$ for $3 \mathrm{~min}$, raised to $160^{\circ} \mathrm{C}$ at $4^{\circ} \mathrm{C} / \mathrm{min}$, then raised to $230^{\circ} \mathrm{C}$ at $7^{\circ} \mathrm{C} / \mathrm{min}$ for $8 \mathrm{~min}$. The transfer line temperature was $230^{\circ} \mathrm{C}$ and the injection temperature was $250^{\circ} \mathrm{C}$. Mass spectra were recorded in electron impact (EI) ionisation mode. Mass spectrometry: mass range 33 to $450 \mathrm{amu}$, scanned at $1 \mathrm{~s}$ intervals. The ion source temperature was $230^{\circ} \mathrm{C}$.

\section{Qualitative analysis and quantification}

The identification of volatile compounds was achieved by comparing mass spectra obtained from the sample with those from pure standards injected in the same conditions, and by comparing the Kovats index or the mass spectra found in the NIST2.0 MS library database or in the literature. An internal standard quantification method using octan-3-ol was employed. Quantitative data of the identified compounds were obtained by interpolation of the relative areas versus the internal standard area using calibration graphs built for pure reference compounds. The concentration of volatile compounds, for which there was no pure reference, was obtained by using the same calibration graphs as the compounds with the most similar chemical structure according to formula and chemical character(Tao et al., 2008). 


\section{Sensory evaluation}

The sensory analysis was developed by the expert panel in sensory analysis - a panel of 30 judges consisting of teachers and graduate students from the College of Enology, Northwest A \& F University. They all had extensive knowledge of wines and had previously participated in wine descriptive sensory analysis training programmes. The descriptive sensory analysis provides the visual aspect, aroma, taste and harmony of the wine samples, which accounted for 15, 30, 44 and 11 scores respectively. Panellists were also trained with Le Nez du Vin (54 aroma terms) over 70 days to assess wine aroma. The wines were coded randomly and were presented to the panel arbitrarily.

\section{Statistical analysis}

Significant differences were assessed with one-way analysis of variance (ANOVA) using the SPSS version 17 statistical package for Windows (SPSS, Chicago, IL). Statistical differences between the means were evaluated using Duncan's test at the $\mathrm{p}=0.05$ level. Discriminant analysis was performed on the wines from different regions using the bound aroma fraction as differentiating variable.

\section{RESULTS}

\section{Analysis of volatile composition}

Volatile compounds in Merlot wines from the four districts detected by SPME-GC-MS are shown in Table 1. Fifty-seven aroma compounds were identified and their concentrations varied from $1 \mu \mathrm{g} / \mathrm{L}$ to $495 \mathrm{mg} / \mathrm{L}$. The majority of the compounds were higher alcohols, esters and organic acids. The trace compounds were terpenols, norisoprenoids and volatile phenols. According to the ANOVA, there was a significant difference between four wine samples in relation to the number of volatile compounds detected. Table 1 shows that more volatile compounds were found in the wines from Changli and Helanshan. The odour active values of these potential aroma active compounds are shown in Table 2. Active odour compounds in wines from Changli, Helanshan, Shacheng and Manasi amounted to 18, 14, 16 and 21 respectively.

In our work, 13 of the 19 esters detected in sample wines were active and had aroma impact. Wines from Changli and Manasi had a higher accumulation of odour active values. Table 2 shows that ethyl hexanoate, ethyl octanoate, isopentyl acetate and ethyl butyrate had higher OAVs than the others, with fruity flavours of banana, strawberry, pineapple and pear. Ethyl acetate and ethyl lactate were active in almost all the wine samples and contributed to sweet flavour and lactic odour. Some esters, such as phenyl ethyl acetate, isopentyl acetate, ethyl DL 2-hydroxy-3-methyl butyrate, ethyl decanoate, isopentyl lactic and isopentyl octanoate, were active only in wines from one or two districts. Higher alcohols were the most abundant volatiles in the sample wines, amounting to $70 \%$ of all volatiles detected. However, only eight of the 20 higher alcohols detected had concentrations over their respective olfactory thresholds. As shown in Table 2, isopentanol, 3-methyl-1-pentanol and $\beta$-phenyl ethanol were odour active in all the samples. Five fatty acids, isobutyric acid, 2-methyl butyric acid, hexanoic acid, octanoic acid and decanoic acid, were detected in the sample wines. Four of them had OAVs $>1$ in one or more wines.
Concerning trace volatile compounds, $\alpha$-ionol, $\beta$-ionol and $\beta$-damascenone were detected in the sample wines. They had a potential aroma contribution. $\beta$-Damascenon had an OAV $>1$ in all the wines. Five terpenols were detected in the sample wines: linalool, linalool oxide, 4-terpineol, citronellol, trans-geraniol and trans-nerolidol. Linalool had an OAV $>1$ in the wines from Changli, Shacheng and Manasi. Citronellol also was active in the Manasi wine. One volatile phenol, 2,4-di-tert-butyl-phenol, was quantified in the sample wines, and it had activity.

\section{Sensory analysis}

Sensory data were collected from a visual, aroma, taste and global evaluation by panellists with wine-tasting training. The results are shown in Table 3. Shacheng wine had better visual scores. Changli wine had better aroma. Manasi wine had the worst evaluation of aroma, taste and harmony. Therefore, Changli wine received the highest sensory scores, while Manasi wine was in last position in the sensory evaluation.

\section{DISCUSSION \\ Major compounds}

Although OAV does not consider the synergism between and suppression among odorants, it seems to be the basic way to predict wine aroma (Ferreira et al., 2000; Moyano et al., 2002). Only those compounds of which the concentrations exceed their respective olfactory thresholds could contribute to the odour. Esters are the main odour active compounds in wine, contributing both fruity and floral flavours. Three kinds of esters have been found in wine, namely acetates esters, ethyl esters, and other esters of fusels and fatty acids ( $\mathrm{Li}$, 2006). Gil et al. (2006) investigated the aroma compositions of white wines and rosé wines from Madrid, Spain and found that ethyl octanoate, ethyl hexanoate, isoamyl acetate and isoamyl alcohol had higher OAV values than the other esters. According to the OAVs and odour description of active esters in Table 2, the aroma prediction of sample wines is possible. Merlot wines from the four districts had obviously fruity traits of banana, pineapple, strawberry and pear. The wines from Changli and Manasi had a higher aroma intensity from esters, which had higher OAV accumulation. In addition, Changli wine had lactic and nut odours, and also some flowery nuances. Helanshan wine had lactic traits. Manasi wine had more nuances of lactic and cream (Sun \& Liu , 2004).

Some researchers have concluded that certain alcohols have aroma, such as 1-butanol, isobutanol, isopentanol, 1-hexanol, 1-pentanol, benzyl alcohol, $\beta$-phenyl ethanol and 3-hexene-1-alcohol (Gil et al., 2006; Vilanova \& Martinez, 2007). Active alcohols in the sample wines showed that all wines had odours of fusel alcohol, soil and flower pollen. In addition, Changli wine had much fusel odour and green grass nuances. Wine from Helanshan had weak fusel and smelled of lemon. Shacheng wine had green grass nuances. Manasi wine had an unpleasant fusel odour, obvious green grass nuances and some flowery traits.

Isobutyric acid, butyric acid, isovaleric acid, hexanoic acid, octanoic acid, decanoic acid, 9-decenoic acid and lauric acid have been reported in previous research (Ferreira et al., 2000; Kotseridis \& Baumes, 2000; Gil et al., 2006; Li et al., 2008). Although $\mathrm{C}_{6}$ to $\mathrm{C}_{10}$ fatty acids are related to 
TABLE 1

Volatile compounds detected by SPME-GC-MS in Merlot wines from four districts in China.

\begin{tabular}{|c|c|c|c|c|c|c|c|}
\hline \multirow[t]{2}{*}{ No. } & \multirow{2}{*}{$\begin{array}{c}\text { RT } \\
\text { (min.) }\end{array}$} & \multirow[t]{2}{*}{ Compounds } & \multicolumn{4}{|c|}{ Concentration $(\mathrm{mg} / \mathrm{L})$} & \multirow{2}{*}{$\begin{array}{l}\text { Odour threshold } \\
\qquad(\mu \mathrm{g} / \mathrm{L})\end{array}$} \\
\hline & & & Changli & Helanshan & Shacheng & Manasi & \\
\hline 1 & 3.26 & ethyl acetate & $51.122 \mathrm{c}$ & $18.205 \mathrm{~b}$ & $17.667 \mathrm{a}$ & $111.434 \mathrm{~d}$ & 7500 \\
\hline 2 & 6.15 & ethyl butyrate & $1.149 \mathrm{c}$ & $0.663 \mathrm{~b}$ & $0.709 \mathrm{~b}$ & $0 \quad \mathrm{a}$ & 20 \\
\hline 3 & 6.54 & 1-propanol & $4.152 \mathrm{~b}$ & $9.723 \mathrm{~d}$ & $5.731 \mathrm{c}$ & 0 & 50000 \\
\hline 4 & 6.96 & ethyl isovalerate & $0.078 \mathrm{c}$ & $0 \mathrm{a}$ & $0.035 \mathrm{~b}$ & 0 & 3 \\
\hline 5 & 8.14 & isobutanol & $38.925 \mathrm{~b}$ & $36.081 \mathrm{a}$ & $39.616 \mathrm{c}$ & $70.329 \mathrm{~d}$ & 40000 \\
\hline 6 & 8.36 & isopentyl acetate & $0.808 \mathrm{c}$ & $0.404 \mathrm{~b}$ & $0.219 \mathrm{a}$ & $2.557 \mathrm{~d}$ & 30 \\
\hline 7 & 9.66 & 1-butanol & $1.1 \mathrm{a}$ & $4.86 \mathrm{~d}$ & $3.784 \mathrm{c}$ & $3.339 \mathrm{~b}$ & 150000 \\
\hline 8 & 11.59 & isopentanol & $306.059 \mathrm{c}$ & $281.69 \mathrm{~b}$ & $262.037 \mathrm{a}$ & $495.457 \mathrm{~d}$ & 30000 \\
\hline 9 & 12.03 & ethyl hexanoate & $0.758 \mathrm{~b}$ & $0.371 \mathrm{a}$ & $0.917 \mathrm{c}$ & $1.199 \mathrm{~d}$ & 14 \\
\hline 10 & 13.72 & 3-hydroxy-2-butanone & $0 \mathrm{a}$ & $0 \mathrm{a}$ & $0 \mathrm{a}$ & $10.184 \mathrm{~b}$ & 150000 \\
\hline 11 & 13.84 & 2-O-2-phenylethyl formate & $0.573 \mathrm{a}$ & $0.591 \mathrm{a}$ & $0.681 \mathrm{~b}$ & $2.378 \mathrm{c}$ & n.d. \\
\hline 12 & 14.99 & isohexyl alcohol & $0.247 \mathrm{a}$ & $0.315 \mathrm{~b}$ & $0.354 \mathrm{c}$ & $0.72 \mathrm{~d}$ & $5000[*]$ \\
\hline 13 & 15.20 & 2-heptanol & $0 \mathrm{a}$ & $0.29 \mathrm{~b}$ & $0 \mathrm{a}$ & $0 \mathrm{a}$ & $250[*]$ \\
\hline 14 & 15.40 & 3-methyl-1-pentanol & $0.495 \mathrm{a}$ & $0.65 \mathrm{~b}$ & $0.683 \mathrm{c}$ & $1.578 \mathrm{~d}$ & $500[*]$ \\
\hline 15 & 15.80 & ethyl lactate & $97.516 \mathrm{c}$ & $29.136 \mathrm{a}$ & $40.78 \mathrm{~b}$ & $175.058 \mathrm{~d}$ & 14000 \\
\hline 16 & 16.24 & 1-hexanol & $9.319 \mathrm{~b}$ & $6.508 \mathrm{a}$ & $10.39 \mathrm{c}$ & $29.466 \mathrm{~d}$ & 8000 \\
\hline 17 & 16.56 & (E)-3-hexen-1-ol & $0.16 \mathrm{~b}$ & $0.123 \mathrm{~b}$ & $0.31 \mathrm{c}$ & $0 \mathrm{a}$ & 400 \\
\hline 18 & 16.95 & 3-ethoxy-1-propanol & $0.566 \mathrm{~b}$ & 0 a & $0 \mathrm{a}$ & $0 \mathrm{a}$ & 100 \\
\hline 19 & 17.20 & (Z)-3-hexen-1-ol & $0 \mathrm{a}$ & $0.154 \mathrm{~b}$ & $0 \mathrm{a}$ & $0 \mathrm{a}$ & 400 \\
\hline 20 & 17.93 & (E)-2-hexen-1-ol & $0 \mathrm{a}$ & $0.107 \mathrm{~b}$ & 0 a & $0 \mathrm{a}$ & 400 \\
\hline 21 & 18.43 & ethyl DL 2-hydroxy -3-methyl butyrate & $0.671 \mathrm{c}$ & $7.574 \mathrm{~d}$ & $0.168 \mathrm{~b}$ & $0 \mathrm{a}$ & 1000 \\
\hline 22 & 18.69 & ethyl octanoate & $0.525 \mathrm{~b}$ & $0.542 \mathrm{c}$ & $0.336 \mathrm{a}$ & $1.092 \mathrm{~d}$ & 5 \\
\hline 23 & 19.51 & 1-heptanol & $0.154 \mathrm{~b}$ & $0.024 \mathrm{a}$ & $0.042 \mathrm{a}$ & $0.211 \mathrm{c}$ & $250[*]$ \\
\hline 24 & 19.87 & linalool oxide & $0 \mathrm{a}$ & $0.013 \mathrm{a}$ & $0 \mathrm{a}$ & $0 \mathrm{a}$ & 500 \\
\hline 25 & 20.58 & 2-ethyl hexanol & $0.098 \mathrm{~d}$ & $0.041 \mathrm{c}$ & $0.03 \mathrm{~b}$ & $0 \mathrm{a}$ & $8000[*]$ \\
\hline 26 & 21.39 & $\beta$-ionone & $0.007 \mathrm{a}$ & 0 a & $0.002 \mathrm{a}$ & $0 \mathrm{a}$ & 0.09 \\
\hline 27 & 21.48 & $\alpha$-ionone & $0.011 \mathrm{a}$ & $0 \mathrm{a}$ & $0 \mathrm{a}$ & $0 \mathrm{a}$ & 0.09 \\
\hline 28 & 22.30 & linalool & $0.038 \mathrm{a}$ & $0.024 \mathrm{a}$ & $0.027 \mathrm{a}$ & $0.202 \mathrm{~b}$ & 25 \\
\hline 29 & 22.67 & 1-octanol & $0.119 b$ & $0.113 \mathrm{~b}$ & $0.068 \mathrm{a}$ & $0.163 \mathrm{c}$ & 900 \\
\hline 30 & 22.89 & isopentyl lactate & $0.563 \mathrm{c}$ & $0.069 \mathrm{a}$ & $0.097 \mathrm{a}$ & $0.387 \mathrm{~b}$ & $200[*]$ \\
\hline 31 & 23.08 & isobutyric acid & $0 \mathrm{a}$ & $0 \mathrm{a}$ & $0.086 \mathrm{a}$ & $0 \mathrm{a}$ & 8100 \\
\hline 32 & 23.25 & 2,3-butanediol & $1.536 \mathrm{c}$ & $1.099 \mathrm{~b}$ & $0.697 \mathrm{a}$ & $10.197 \mathrm{~d}$ & 120000 \\
\hline 33 & 24.91 & ethyl decanoate & $0.03 \mathrm{a}$ & $0.077 \mathrm{~b}$ & $0.038 \mathrm{a}$ & $0.233 \mathrm{c}$ & 200 \\
\hline 34 & 25.49 & isopentyl octanoate & $0.092 \mathrm{c}$ & $0 \mathrm{a}$ & $0.058 \mathrm{~b}$ & $0.48 \mathrm{~d}$ & 125 \\
\hline 35 & 25.98 & diethyl succinate & $40.601 \mathrm{c}$ & $2.424 \mathrm{a}$ & $17.669 \mathrm{~b}$ & $142.932 \mathrm{~d}$ & 200000 \\
\hline 36 & 26.10 & 2-methyl butyric acid & $0 \mathrm{a}$ & $0.126 \mathrm{a}$ & $0 \mathrm{a}$ & $0 \mathrm{a}$ & 50 \\
\hline 37 & 26.40 & ethyl 9-decenoate & $0.003 \mathrm{a}$ & $0.001 \mathrm{a}$ & $0.001 \mathrm{a}$ & $0.027 \mathrm{a}$ & $100\left[{ }^{*}\right]$ \\
\hline 38 & 26.62 & $\beta$ - terpineol & $0.081 \mathrm{~b}$ & $0.01 \mathrm{a}$ & $0 \mathrm{a}$ & $0 \mathrm{a}$ & 250 \\
\hline 39 & 27.10 & 3-methyl-1-propanol & $0 \mathrm{a}$ & $0.14 \mathrm{~b}$ & $0.14 \mathrm{~b}$ & $0 \mathrm{a}$ & 1000 \\
\hline 40 & 28.53 & 1-decanol & $0.093 \mathrm{~b}$ & $0 \mathrm{a}$ & $0 \mathrm{a}$ & $0.403 \mathrm{c}$ & 400 \\
\hline 41 & 28.61 & citronellol & $0 \mathrm{a}$ & $0.037 \mathrm{~b}$ & $0.008 \mathrm{a}$ & $0.234 \mathrm{c}$ & 100 \\
\hline 42 & 28.92 & ethyl phenyl-acetate & $0.223 \mathrm{~b}$ & $0 \mathrm{a}$ & $0 \mathrm{a}$ & $0 \mathrm{a}$ & $650[*]$ \\
\hline 43 & 29.71 & phenethyl acetate & $0.262 \mathrm{c}$ & $0.19 \mathrm{~b}$ & $0.071 \mathrm{a}$ & $1.444 \mathrm{~d}$ & 250 \\
\hline 44 & 29.86 & $\beta$-damascenone & $0.011 \mathrm{a}$ & $0.005 \mathrm{a}$ & $0.001 \mathrm{a}$ & $0.023 \mathrm{a}$ & 0.05 \\
\hline 45 & 30.60 & ethyl laurate & $0.002 \mathrm{a}$ & $0.036 \mathrm{a}$ & $0.005 \mathrm{a}$ & $0.054 \mathrm{a}$ & $1500[*]$ \\
\hline 46 & 30.76 & trans-geraniol & $0 \mathrm{a}$ & $0.026 \mathrm{a}$ & $0 \mathrm{a}$ & $0 \mathrm{a}$ & 36 \\
\hline 47 & 30.91 & hexanoic acid & $0.942 \mathrm{c}$ & $0.08 \mathrm{a}$ & $0.485 \mathrm{~b}$ & $3.9 \mathrm{~d}$ & 420 \\
\hline
\end{tabular}


TABLE 1 (CONTINUED).

\begin{tabular}{|c|c|c|c|c|c|c|c|}
\hline \multirow[t]{2}{*}{ No. } & \multirow{2}{*}{$\begin{array}{c}\mathrm{RT} \\
(\min .)\end{array}$} & \multirow[t]{2}{*}{ Compounds } & \multicolumn{4}{|c|}{ Concentration $(\mathrm{mg} / \mathrm{L})$} & \multirow{2}{*}{$\begin{array}{l}\text { Odour threshold } \\
\qquad(\mu \mathrm{g} / \mathrm{L})\end{array}$} \\
\hline & & & Changli & Helanshan & Shacheng & Manasi & \\
\hline 48 & 31.17 & butyl butyrate & $0.082 \mathrm{~b}$ & $0 \mathrm{a}$ & $0 \mathrm{a}$ & $0 \mathrm{a}$ & 100 \\
\hline 49 & 31.34 & benzyl alcohol & $1.789 \mathrm{c}$ & $1.545 \mathrm{~b}$ & $0.711 \mathrm{a}$ & $3.377 \mathrm{~d}$ & 200000 \\
\hline 50 & 32.15 & $\beta$-phenyl-ethanol & $95.712 \mathrm{c}$ & $32.601 \mathrm{~b}$ & $31.055 \mathrm{a}$ & $323.366 \mathrm{~d}$ & 14000 \\
\hline 51 & 33.44 & lauryl alcohol & $0.038 \mathrm{a}$ & $0.016 \mathrm{a}$ & $0 \mathrm{a}$ & $0 \mathrm{a}$ & $1000[4]$ \\
\hline 52 & 34.76 & {$[E]$-nerolidol } & $0.023 \mathrm{a}$ & $0.016 \mathrm{a}$ & $0.007 \mathrm{a}$ & $0.239 \mathrm{~b}$ & $700[*]$ \\
\hline 53 & 34.90 & ethyl myristate & $0.001 \mathrm{a}$ & $0.001 \mathrm{a}$ & $0 \mathrm{a}$ & $0 \mathrm{a}$ & $2000[*]$ \\
\hline 54 & 35.24 & octanoic acid & $3.23 \mathrm{c}$ & $0.885 \mathrm{a}$ & $1.369 \mathrm{~b}$ & $13.207 \mathrm{~d}$ & 500 \\
\hline 55 & 38.15 & ethyl palmitate & $0.002 \mathrm{a}$ & $0.001 \mathrm{a}$ & $0 \mathrm{a}$ & $0 \mathrm{a}$ & 1500 \\
\hline 56 & 38.59 & n-decanoic acid & $0.191 \mathrm{c}$ & $0.037 \mathrm{~b}$ & $0.097 \mathrm{a}$ & $1.765 \mathrm{~d}$ & 1000 \\
\hline \multirow[t]{2}{*}{57} & 38.94 & 2,4-di-tert-butyl-phenol & $0.207 \mathrm{c}$ & $0.088 \mathrm{~b}$ & $0.048 \mathrm{a}$ & $0.51 \mathrm{~d}$ & 200 \\
\hline & & Total & 660.364 & 437.712 & 437.229 & 1408.145 & \\
\hline
\end{tabular}

(a) The references from which the odour thresholds have been taken are Li (2006); Li et al. (2008); Tao et al. (2008); Tao \& Yang (2010).

[*] Calculated in the Laboratory of Wine Olfactometry, College of Enology, Northwest A \& F University, China. Orthonasal thresholds were calculated in a $12 \%$ ethanol/water mixture containing $5 \mathrm{~g} / \mathrm{L}$ tartaric acid at $\mathrm{pH} 3.2$.

n.d., not detected.

Means with the same letter do not differ significantly by Duncan's test $(\mathrm{p}<0.05)$.

negative flavours in wine, they are important in the balance of aroma compounds as they can restrain the hydrolysis of aromatic esters (Edwards et al., 1990). Shinohara (1985) showed that $\mathrm{C}_{6}$ to $\mathrm{C}_{10}$ fatty acids gave the smell of cheese and cream at concentrations of 4 to $10 \mathrm{mg} / \mathrm{L}$, while they emitted an unpleasant fatty odour, and even a rancid smell, when present at higher concentrations $(>20 \mathrm{mg} / \mathrm{L})$. In this work, Changli wine had the appropriate content of fatty acids, which could contribute a pleasant, fatty smell, but also retain a sufficient content of aromatic esters. The wines from Helanshan and Shacheng had somewhat lower contents of fatty acids. However, Manasi wine had a much higher content of fatty acids, and hence also an obvious rancid odour.

\section{Trace compounds}

Trace compounds in wine may contribute to global aroma due to their very low olfactory threshold. $\alpha$-Ionol, $\beta$-ionol and $\beta$-damascenone are three norisoprenoids that are often reported (Boido et al., 2003; Lopez et al., 2004; GómezMíguez et al., 2007; Vilanova \& Martinez, 2007). They have concentrations $<10 \mu \mathrm{g} / \mathrm{L}$ in wine generally. Because their olfactory threshold is very low, between 0.05 and $0.09 \mu \mathrm{g} / \mathrm{L}$, they usually have odour activity. In our work, $\beta$-damascenone was active in all the samples, providing the flavour of processed fruit, such as canned peach, and baked apple. $\alpha$-Ionol was active in the Changli wine, and $\beta$-iono in the Changli and Shacheng wine. These two compounds smelled of raspberry and added violet flavour.

Numerous studies have reported that the terpenoid compounds could be used analytically for varietal characterisation. Terpene compounds are one class of plant secondary metabolites whose biosynthesis begins with acetyl-coenzyme A (CoA). Terpenes are not changed by yeast metabolism during fermentation and differ between varieties (José et al., 2004; Câmara et al., 2007; Falque et al., 2008). According to the monoterpenes content in grape juices, three grape classes can be classified: 1) muscat varieties, with monoterpenes more than $6 \mathrm{mg} / \mathrm{L}$, 2) non-muscat but aromatic varieties, with monoterpenes at 1 to $4 \mathrm{mg} / \mathrm{L}$, and 3) neutral varieties not dependent upon monoterpenes for their odour (Mateo \& Jiménez, 2000). Terpene compounds in wine are almost terpenols. Merlot is a neutral variety. In this work, linalool had an OAV $>1$ in the Changli, Shacheng and Manasi wine samples, and added muscat flavour. Citronellol was active in Manasi wine and provided traits of clove and rosebush.

Volatile phenols are another class of potential active odorants in wine, such as guaiacol, cresol, 4-ethyl phenol, vinyl phenol, eugenol, vanilla, etc. They are mostly soluble compounds extracted from oak barrels during ageing. In this work, the sample wines were not stored in oak barrels, hence only 2,4-di-tert-butyl-phenol was detected and expressed any phenolic odour activity in the Changli and Manasi wines.

\section{Sensory analysis}

Sensory analysis confirmed the contributions of the active odorants in the samples. Changli wine had much higher levels of impact odorants and OAV accumulation. Its aroma was complex and pleasant. Manasi wine also had higher impact odorants, but its short-chain fatty acids and volatile phenol gave an off-flavour, a bad taste and poor harmony. As highlighted in the work of Aznar et al. (2003), overall pleasant descriptions are positively correlated with the chemicals with a pleasant aroma, but unpleasant compounds have a much more destructive effect on global aroma quality.

\section{CONCLUSIONS}

The differences in sensory and aroma composition profiles of Merlot wines from different geographic origins were characterised successfully. Fifty-seven volatile compounds were identified in Merlot wines in China, 31 of which are active odorants. Furthermore, some aroma compounds 
TABLE 2

OAVs and odour descriptions of impact odorants in Merlot wines from four districts in China.

\begin{tabular}{|c|c|c|c|c|c|c|c|}
\hline \multirow[t]{2}{*}{ No. } & \multirow{2}{*}{$\begin{array}{c}\text { RT } \\
\text { (min.) }\end{array}$} & \multirow[t]{2}{*}{ Compounds } & \multicolumn{4}{|c|}{$\mathrm{OAVs}^{\mathrm{a}}$} & \multirow[t]{2}{*}{ Odour description $^{b}$} \\
\hline & & & Changli & Helanshan & Shacheng & Manasi & \\
\hline & & Acetate esters & & & & & \\
\hline 1 & 3.26 & ethyl acetate & 6.8 & 2.4 & 2.4 & 14.9 & fruity, sweet \\
\hline 2 & 8.39 & isopentyl acetate & 26.9 & 13.5 & 7.3 & 85.2 & banana \\
\hline \multirow[t]{3}{*}{3} & 29.71 & phenethyl acetate & 1.0 & 0.8 & 0.3 & 5.8 & pleasant, floral \\
\hline & & Sum & 34.8 & 16.7 & 9.9 & 105.9 & \\
\hline & & Ethyl esters & & & & & \\
\hline 1 & 6.15 & ethyl butyrate & 57.5 & 33.2 & 35.5 & & sour fruit, strawberry, fruity \\
\hline 2 & 6.97 & ethyl isovalerate & 26.0 & & 11.7 & & banana, sweet fruity \\
\hline 3 & 12.03 & ethyl hexanoate & 54.1 & 26.5 & 65.5 & 85.6 & green apple, fruity, strawberry, anise \\
\hline 4 & 15.80 & ethyl lactate & 7.0 & 2.1 & 2.9 & 12.5 & lactic, raspberry \\
\hline 5 & 18.43 & ethyl DL 2-hydroxy-3-methyl butyrate & 0.7 & 7.6 & 0.2 & & pineapple, strawberry, tea, honey \\
\hline 6 & 18.71 & ethyl octanoate & 105.0 & 108.4 & 67.2 & 218.4 & pineapple, pear, floral \\
\hline \multirow[t]{3}{*}{7} & 24.93 & ethyl decanoate & 0.2 & 0.4 & 0.2 & 1.2 & fruity, pleasant fatty \\
\hline & & Sum & 250.4 & 178.1 & 183.1 & 317.7 & \\
\hline & & Other esters & & & & & \\
\hline 1 & 22.89 & isopentyl lactate & 2.8 & 0.3 & 0.5 & 1.9 & cream, nut \\
\hline \multirow[t]{3}{*}{2} & 25.67 & isopentyl octanoate & 0.7 & & 0.5 & 3.8 & sweet, cheese, cream, light fruity \\
\hline & & Sum & 3.6 & 0.3 & 0.9 & 5.8 & \\
\hline & & Higher alcohols & & & & & \\
\hline 1 & 8.21 & isobutanol & 1.0 & 0.9 & 1.0 & 1.8 & fusel, alcohol \\
\hline 2 & 11.59 & isopentanol & 10.2 & 9.4 & 8.7 & 16.5 & alcohol, harsh, bitter \\
\hline 3 & 15.20 & 2-heptanol & & 1.2 & & & lemon, orange, copper \\
\hline 4 & 15.38 & 3-methyl-1-pentanol & 1.0 & 1.3 & 1.4 & 3.2 & soil, mushroom \\
\hline 5 & 16.24 & 1-hexanol & 1.2 & 0.8 & 1.3 & 3.7 & green, grass \\
\hline 6 & 16.95 & 3-ethoxy-1-propanol & 5.7 & & & & fusel, alcohol \\
\hline 7 & 28.53 & 1-decanol & 0.2 & & & 1.0 & orange flowery, especially fatty \\
\hline \multirow[t]{3}{*}{8} & 32.15 & $\beta$-phenyl-ethanol & 6.8 & 2.3 & 2.2 & 23.1 & floral, pollen, perfume \\
\hline & & Sum & 26.1 & 15.9 & 14.6 & 65.9 & \\
\hline & & Organic acids & & & & & \\
\hline 1 & 26.10 & 2-methyl butyric acid & 0.0 & 2.5 & 0.0 & 0.0 & cheese \\
\hline 2 & 30.89 & hexanoic acid & 2.2 & 0.2 & 1.2 & 9.3 & cheese, rancid \\
\hline 3 & 35.23 & octanoic acid & 6.5 & 1.8 & 2.7 & 26.4 & cheese, fatty acid, harsh, rancid \\
\hline \multirow[t]{3}{*}{4} & 38.59 & decanoic acid & 0.2 & 0.0 & 0.1 & 1.8 & fatty, unpleasant \\
\hline & & Sum & 8.9 & 4.5 & 4.0 & 37.5 & \\
\hline & & Terpenols & & & & & \\
\hline 1 & 22.32 & linalool & 1.5 & 1.0 & 1.1 & 8.1 & muscat, flowery, fruity \\
\hline \multirow[t]{3}{*}{2} & 28.61 & citronellol & 0.0 & 0.4 & 0.1 & 2.3 & clove, rosebush \\
\hline & & Sum & 1.5 & 1.4 & 1.2 & 10.4 & \\
\hline & & Norisoprenoids & & & & & \\
\hline 1 & 21.45 & $\beta$-ionone & 77.8 & & 22.2 & & raspberry, violet, sweet fruity \\
\hline 2 & 21.54 & $\alpha$-ionone & 122.2 & & & & raspberry, violet, sweet fruity \\
\hline \multirow[t]{3}{*}{3} & 29.86 & $\beta$-damascenone & 220.0 & 100.0 & 20.0 & 460.0 & bark, canned peach, baked apple, dry plum \\
\hline & & Sum & 420.0 & 100.0 & 42.2 & 460.0 & \\
\hline & & Others & & & & & \\
\hline \multirow[t]{2}{*}{1} & 38.94 & 2,4-di-tert-butyl-phenol & 1.0 & 0.4 & 0.2 & 2.6 & phenolic \\
\hline & & Sum & 1.0 & 0.4 & 0.2 & 2.6 & \\
\hline
\end{tabular}

a: Odour activity values were calculated by dividing the concentration by the odour threshold value of the compound. b: The odour descriptions are cited in the references of Sun \& Liu (2004); Li (2006); Li et al. (2008); Tao et al. (2008). 
TABLE 3

Results of the sensory analysis of Merlot wines from four districts in China.

\begin{tabular}{llcccc}
\hline & Sensory attributes & Changli & Helanshan & Shacheng & Manasi \\
\hline Visual & Clarity (5) & 4.2 & 4.3 & 4.2 & 4.3 \\
& Appearance (10) & 6.7 & 6.8 & 7.1 & 6.5 \\
\hline Aroma & Purity (6) & 5.5 & 5.2 & 4.8 & 3.7 \\
& Intensity (8) & 7.5 & 6.2 & 6.5 & 6.9 \\
& Quality (16) & 14.5 & 12.2 & 5.3 & 10.9 \\
\hline Taste & Purity (6) & 5.5 & 5.4 & 5.5 & 5.1 \\
& Intensity (8) & 7.2 & 7.1 & 7.4 & 7.5 \\
& Prolongation (8) & 7.3 & 6.8 & 7.5 & 6.5 \\
\hline Global evaluation & Quality (22) & 20.5 & 21.4 & 20.6 & 17.3 \\
\hline Total* & Harmony (11) & 10.1 & 10.2 & 10.2 & 9.5 \\
\hline
\end{tabular}

$*>86=$ Excellent; $81-85=$ very good; $71-80=$ good; $50-70=$ regular; $<50=$ inadequate

were only active in the wines from one or two districts. Changli wine was found to have an appropriate content of fatty acids. The content of fatty acids in Manas wine was much higher, while it was lower in the Helanshan and Shacheng wines. Changli wine had a higher fruity aroma, obvious lactic and nut traits, and other complex flavours.

The sensory analysis validated the aroma contributions of the active odorants of the sample wines. More pleasant impact odorants gave Changli wine a better aroma and good sensory quality. Too much fatty acid and volatile phenol destroyed the aroma quality of the Manasi wine and resulted in this wine receiving the worst evaluation of aroma, taste and harmony.

\section{LITERATURE CITED}

Allen, M.S., Lacey, M.J. \& Boyd, S., 1994. Determination of methoxypyrazine in red wine by stable isotope dilution gas chromatographymass spectrometry. J. Agric. Food Chem. 42, 1734-1738.

Aznar, M., Lopez, R., Cacho, J. \& Ferreira, V., 2003. Prediction of aged red wine aroma properties from aroma chemical composition. Partial least squares regression models. J. Agric. Food Chem. 51, 2700-2707.

Boido, E., Lloret, A., Medina, K., Farina, L., Carrau, F., Versini, G. \& Dellacassa, E., 2003. Aroma composition of Vitis vinifera cv. Tannat: the typical red wine from Uruguay. J. Agric. Food Chem. 51, 5408-5413.

Câmara, J.S., Alves, M.A. \& Marques, J.C., 2007. Classification of Boal, Malvazia, Sercial and Verdelho wines based on terpenoid patterns. Food Chem. 101, 475-484.

Culleré, L., Escudero, A., Cacho, J. \& Ferreira, V., 2004. Gas chromatography-olfactory and chemical qualitative study of the aroma of six premium quality Spanish aged red wines. J. Agric. Food Chem. 52, 1653-1660.

Diaz, C., Conde, J.E., Mendez, J.J. \& Trujillo, J.P.P., 2003. Volatile compounds of bottled wines with denomination of origin from the Canary Islands (Spain). Food Chem. 81, 447-452.

Edwards, C.G., Beelman, R.B., Bartley, C.E. \& McConnell, A.L., 1990. Production of decanoic acid and other volatile compounds and the growth of yeast and malolactic bacteria during vinification. Am. J. Enol. Vitic. 41, 48-56.
Escudero, A., Gogorza, B., Melusa, M.A., Ortian, N., Cachi, J. \& Ferreira, V., 2004. Characterization of the aroma of a wine from Maccabeo. Key role played by compounds with low odor activity values. J. Agric. Food Chem. $52,3516-3524$.

Falque, E., Darriet, P., Fernandez, E. \& Dubourdieu, D., 2008. Volatile profile and differentiation between Albarino wines from different origins. Int. J. Food Sci. Tech. 43, 464-475.

Ferreira, V., Lopez, R. \& Cacho, J.F., 2000. Quantitative determination of the odorants of young red wines from different grape varieties. J. Sci. Food Agr. 80, 1659-1667.

Gil, M., Cabellos, J.M., Arroyo, T. \& Prodanov, M., 2006. Characterization of the volatile fraction of young wines from the Denomination of Origin "Vinos de Madrid" (Spain). Anal. Chim. Acta. 563, 145-153.

Gómez-Míguez, M.J., Cacho, J.F., Ferreira, V., Vicario, I.M. \& Heredia, F.J., 2007. Volatile components of Zalema white wines. Food Chem. 100, 1464-1473.

Gurbuz, O., Rouseff, J.M., Rouseff, R.L., 2006. Comparison of aroma volatiles in commercial Merlot and Cabernet Sauvignon wines using gas chromatography-olfactometry and gas chromatography-mass spectrometry. J. Agric. Food Chem. 54, 3990-3996.

Guth, H., 1997. Quantitation and sensory studies of character impact odorants of different white wine varieties. J. Agric. Food Chem. 45, 30273032 .

Kotseridis, Y. \& Baumes, R., 2000. Identification of impact odorants in Bordeaux red grape juice, in the commercial yeast used for its fermentation, and in the produced wine. J. Agric. Food Chem. 48, 400-406.

Li, H., 2006. Wine tasting. China Science Press, Beijing. pp. 29-106.

Li, H., Tao, Y.S., Wang, H. \& Zhang, L., 2008. Impact odorants of Chardonnay dry white wine from Changli County (China). Eur. Food Res. Technol. 227, 287-292.

Lopez, R., Ferreira, V., Hernamde, Z.P. \& Cacho, J.F., 1999. Identification of impact odorants of young red wines made with Merlot, Cabernet Sauvignon and Grenache grape varieties: a comparative study. J. Sci. Food Agr. 79, 1461-1467.

Lopez, R., Ezpeleta, E., Sanchez, I., Cacho, J. \& Ferreira, V., 2004. Analysis of the aroma intensities of volatile compounds released from mild acid hydrolysates of odourless precursors extracted from Tempranillo and Grenache grapes using gas chromatography-olfactometry. Food Chem. 88, 95-103. 
Mateo, J.J. \& Jiménez, M., 2000. Monoterpenes in grape juice and wines. J. Chromatogra. A. 881, 557-567.

Moyano, L., Zea, L., Moreno, J. \& Medina, M., 2002. Analytical study of aromatic series in sherry wines subjected to biological aging. J. Agric. Food Chem. 50, 7356-7361.

O.I.V., 1990. Recueil des methods internationals d'analyse des vins et des mouts. Office International de la Vigne et du Vin, Paris.

Oliveira, J.M., Araújo, I.M., Pereira, O.M., Maia, J.S., Amaral, A.J. \& Mia M.O., 2004. Characterization and differentiation of five "Vinhos Verdes" grape varieties on the basis of monoterpenic compounds. Anal. Chim. Acta. $513,269-275$.

Perestrelo, R., Fernandes, A., Albuquerque, F.F., Marques, J.C. \& Camara, J.S., 2006. Analytical characterization of the aroma of Tinta Negra Mole red wine: identification of the main odorants compounds. Anal. Chim. Acta. $563,154-164$.

Peynaud, E., 1980. Le Goût du Vin. Dunod, Paris.
Shinohara, T., 1985. Gas chromatographic analysis of volatile fatty acids in wines. Agr. Biol. Chem. 49, 2211-2212.

Sun, B.G. \& Liu, Y. P., 2004. Food spice and flavor handbook. China Petroleum Press, PLACE OF PUBLICATION?

Tao, Y.S. \& Zhang, L., 2010. Intensity prediction of typical aroma characters of Cabernet Sauvignon wine in Changli County (China) . LWT-Food Sci. Technol. 43, 1550-1556.

Tao, Y.S., Li, H., Wang, H. \& Zhang, L., 2008. Volatile compounds of young Cabernet Sauvignon red wine from Changli County (China). J. Food Compos. Anal. 21, 689-694.

Vilanova, M. \& Martinez, C., 2007. First study of determination of aromatic compounds of red wine from Vitis vinifera CV. Castanal grown in Galicia (NW Spain). Eur. Food Res. Technol. 224, 431-436.

Wang, H., Zhang, L., Li, H. \& Liu, L.P., 2005 Analysis of aroma components of Merlot Claret by GC/MS. Liquor-making Sci. \& Technol. 5, 101-103. 